\title{
Application of BAROS' questionnaire in obese patients undergoing bariatric surgery with 2 years of evolution
}

\author{
Caetano de QUEIROZ', José Afonso SALLET², Pedro Gabriel Melo DE BARROS E SILVA', \\ Luzia da Gloria Pereira de Sousa QUEIROZ ${ }^{1}$, Jélis Arenas PIMENTEL ${ }^{2}$ and Paulo Clemente SALLET ${ }^{2}$
}

Received 11/4/2016 Accepted 10/8/2016

\begin{abstract}
Background - In recent decades, the high prevalence of obesity in the general population has brought serious concerns in terms of public health. Contrarily to conventional treatment involving dieting and physical exercising, often ineffective in generating long term results, bariatric operations have been an effective method for sustained weight loss in morbidly obese individuals. The Bariatric Analysis and Reporting Outcome System (BAROS) is an objective and recognized system in the overall evaluation of results after bariatric surgery. Objective - To investigate results concerning a casuistic of morbidly obese patients undergoing bariatric surgery over a 2-year follow-up in terms of weight loss, related medical conditions, safety and changes in quality of life. Methods - A total of 120 obese (17 male and 103 female) patients, who underwent bariatric surgery, were assessed and investigated using the BAROS system after a 2- year follow-up. Results - Patients obtained a mean excess weight loss of 74.6 ( \pm 15.9$) \%$ and mean body mass index reduction of $15.6( \pm 4.4) \mathrm{Kg} / \mathrm{m}^{2}$. Pre-surgical comorbidities were present in $71(59 \%)$ subjects and they were totally $(86 \%)$ or partially $(14 \%)$ resolved. Complications resulting specifically from the surgical procedure were observed in $4.2 \%$ of cases (two bowel obstructions requiring re-operation, and three stomal stenosis treated with endoscopic dilation). Sixteen subjects (13\% of total number of patients) presented minor clinical complications managed through outpatient care. The final scores for the BAROS questionnaire showcased excellent to good results in $99 \%$ of cases (excellent $44 \%$, very good $38 \%$, good $23 \%$, acceptable $1 \%$ ). Conclusion-According to the BAROS questionnaire, bariatric surgery is a safe and effective method for managing obesity and associated clinical comorbidities, allowing for satisfactory results after a 2-year follow-up. Future studies should address other clinical and psychosocial variables that impact outcome as well as allow for longer follow-ups.
\end{abstract}

HEADINGS - Morbid obesity. Bariatric surgery. Body weight. Quality of life.

\section{INTRODUCTION}

In recent decades, the high prevalence of obesity in the general population has brought serious concerns in terms of public health. Overweight and obesity have significantly increased morbidity and mortality around the world due to its associated medical conditions $^{(12)}$.

According to World Health Organization's projections, the situation is even more dramatic because it is estimated that by 2030, approximately two third of the world's population would be overweight or obese $(2.2 / 3.3 \text { billion })^{(11)}$.

According to the IBGE (Brazilian Institute of Geography and Statistics), from 2006 to 2013 the prevalence of obesity (BMI>30) in adults increased from $11.8 \%$ to $17.5 \%$, and for the first time men reached approximately the same obesity rate of women.

Consequently, the increased incidence of overweight and obesity in the Brazilian general population is overloading the public health system (SUS - Unified Public Health System), requiring treatment of these conditions and associated diseases ${ }^{(13)}$.

The burden of obesity is related to serious health consequences associated to obesity, including type- 2 diabetes, cardiovascular disease, musculoskeletal disorders and certain types of cancers.
Some of these conditions are directly related to the principal causes of death, such as heart disease and stroke ${ }^{(16)}$. Several other conditions associated to obesity can lead to a reduced life expectancy and poor quality of life, such as obstructive sleep apnea, infertility, obstetric complications and psychiatric comorbidities ${ }^{(6)}$.

Contrarily to conventional treatment involving dieting and physical exercising, often ineffective in generating long term results ${ }^{(10)}$, bariatric operations have been an effective method for sustained weight loss in morbidly obese individuals ${ }^{(2,7,9)}$.

The Roux-en-Y gastric bypass (RYGBP) limits caloric intake and also reduces calorie absorption. Other mechanisms such as alterations in postprandial circulating levels of gut hormones may also contribute to the weight loss observed after these bariatric operations $^{(4)}$.

However, weight loss is not the only criteria for successful outcome following bariatric surgery, since the improvement in comorbidities and changing health-related quality of life are also very important criteria of outcome, especially for the patient's perspective.

The bariatric analysis and reporting outcome system (BAROS) is an objective and recognized system in the overall evaluation of results after bariatric surgery ${ }^{(17,18)}$. 
The BAROS combines the Moorehead- Ardelt QoL questionnaire, which incorporates questions about self-esteem and activity levels as items impacting QoL, with other data relevant to evaluation of bariatric surgery outcomes, including the percentage of excess weight loss. (\%EWL), improvement in co-morbid conditions, and complications, Therefore, it produces a valid and reliable assessment of the QoL outcomes after weight loss surgery. Several studies have used the BAROS, allowing fairly consistent comparative analysis between various research centers ${ }^{(1,3,14)}$.

The main objectives of the present study are to report results concerning a casuistic of morbidly obese patients undergoing RYGB after a period of 2 years. They were analysed in terms of weight loss, improvement of obesity related medical conditions, and quantitative changes in health-related quality of life (QoL), discussing our results comparatively to the current literature documenting results regarding these outcome variables.

\section{METHODS}

This is a retrospective, descriptive study with a quantitative approach, carried out with a sample of 120 medical records of patients undergoing bariatric surgery, laparoscopic Roux-en-Y gastric bypass (RYGB), at a center of excellence certified by Surgical Review Corporation (SRC) and Brazilian Society of Bariatric And Metabolic Surgery (SBCBM) in 2012 for the realization of such surgery in the state São Paulo (Hospital and Maternity Vitoria). The patient's charts were selected and data were collected through the institution database, using the following inclusion criteria: patients who underwent RYGB between the months of March to June 2011 aged 20 to 50 years.

For the scope of comparison, we conducted a search for articles on the platform PubMed with the keywords: bariatric surgery, RYGB and BAROS.

The calculation of $\% \mathrm{EWL}$ (percent of excess weight loss) was based on the Mean Ideal Weight Women and Men According to Height $^{(15)}$.

Data were collected through the institution database, in order to obtain information concerning the changes occurred on the following items: loss of excess weight, evolution of comorbidities and surgical or clinical complications. The five aspects of quality of life (self-esteem, willingness to physical activity, sociability, willingness to work and sex life) were assessed by telephone calls, according to the BAROS items. This evaluation method using the BAROS instrument allowed us to classify the patients into five groups (poor, acceptable, good, very good or excellent) based on a score table.

Surgical procedures were performed by a team of largely experienced surgeons, according to standard techniques described in routine Roux-en-Y gastric by-pass guidelines (RYGB) ${ }^{(19)}$.

Diagnostic criteria and assessment of clinical co-morbidities, and parameters considered in the analysis of outcome were based on specifications proposed by Oria and Moorehead ${ }^{(17,18)}$. The current analysis followed the ethical aspects described in the Declaration of Helsinki and the Document of the Americas. The protocol and all other applicable documents were approved by the local institutional review board.

\section{Statistics}

Statistics were computed using IBM SPSS statistical package, version 20. In the descriptive statistics, continuous variables were presented as means and standard deviation and categorical variables as frequencies and percentages. Kolmogorov-Smirnov tests were used to test normality of distributions among continuous variables: age, $\mathrm{BMI}$ reduction and $\% \mathrm{EWL}$ showed normal distributions. BAROS scores related to $\% \mathrm{EWL}(P<0.001)$, QoL $(P=0.002)$ and BAROS total scores $(P=0.04)$ showed non-normal distributions. ANOVA and Mann-Whitney tests were used according to the normality of distributions. A maximum limit of significance of 5\% was defined for chance of type I error $(P<0.05)$ in two-tailed tests.

\section{RESULTS}

\section{Clinical demographical data and weight loss results: Results concerning clinical data, baseline and end-point variables in $\mathbf{1 2 0}$ patients}

(103 women and 17 men) are showed in Table 1.

Patients showed highly significant reductions in weight and BMI along the 2-year follow-up period (mean days after surgery $=794( \pm 33)$ days). Overall, mean percent excess weight loss was $74.6( \pm 15.9)$ and $\mathrm{BMI}$ reduction was $15.6( \pm 4.4) \mathrm{Kg} / \mathrm{m}^{2}$. Women showed \%EWL higher than men $(\mathrm{F}=10.7 ; P=0.001)$. However, with reference to BMI reduction, women showed just a non-significant trend to higher reduction comparatively to men $(\mathrm{F}=2.7 ; P=0.102)$.

TABLE 1. Clinical, baseline and 2-year follow-up variables in 120 patients submitted to RYGB

\begin{tabular}{|c|c|c|c|c|c|c|c|c|c|}
\hline Gender & $\begin{array}{c}\text { Age } \\
\text { (years) }\end{array}$ & $\begin{array}{c}\text { Baseline } \\
\text { BMI }\end{array}$ & $\begin{array}{l}\text { Baseline } \\
\text { Weight }\end{array}$ & $\begin{array}{l}\text { Excess } \\
\text { Weight }\end{array}$ & Final Weight & Final BMI & $\begin{array}{c}\text { BMI } \\
\text { Reduction }\end{array}$ & $\begin{array}{c}\% \text { Excess } \\
\text { Weight Loss }\end{array}$ & $\begin{array}{c}\text { Hospital } \\
\text { (days) }\end{array}$ \\
\hline Male $(n=17)$ & $36.2( \pm 7.6)$ & $46.1( \pm 6.4)$ & $152.3( \pm 32.7)$ & $81.5( \pm 31.0)$ & $101.4( \pm 21.4)$ & $32.2( \pm 5.9)$ & $13.9( \pm 5.9)$ & $63.4( \pm 15.5)$ & $3.4( \pm 1.0)$ \\
\hline Female $(\mathrm{n}=103)$ & $36.2( \pm 7.0)$ & $44.2( \pm 4.3)$ & $120.5( \pm 16.2)$ & $61.2( \pm 14.0)$ & $74.7( \pm 12.5)$ & $28.3( \pm 4.3)$ & $15.8( \pm 4.1)$ & $76.5( \pm 15.3)$ & $3.4( \pm 1.8)$ \\
\hline Total $(n=120)$ & $36.2( \pm 7.1)$ & $44.5( \pm 4.7)$ & $125.0( \pm 22.2)$ & $64.0( \pm 18.7)$ & $78.5( \pm 16.8)$ & $28.9( \pm 4.8)$ & $15.6( \pm 4.4)$ & $74.6( \pm 15.9)$ & $3.4( \pm 1.7)$ \\
\hline $\begin{array}{l}\text { Statistics } \\
\text { BaseLine:Final }\end{array}$ & & & & & $\begin{array}{l}\mathrm{T}=39.7 \\
\mathrm{df}=119 \\
P<0.000\end{array}$ & $\begin{array}{l}\mathrm{T}=38.4 \\
\mathrm{df}=119 \\
P<0.000\end{array}$ & & & \\
\hline
\end{tabular}

RYGB: Roux-en-Y gastric bypass 


\section{BAROS results}

Results of row scores obtained from the 120 subjects using the BAROS scale are presented on Table 2. Referencing the total score of the BAROS scale, women presented better results comparatively to men (Mann-Whitney $P=0.005$ ). Table 2 shows us that this effect was mainly.
On the other hand, one patient $(0.8 \%$ of total casuistic) suffered major clinical complication requiring hospital admission due to pulmonary embolism as early clinical complication. All complications were solved with specific clinical measures or surgical procedures during hospitalizations shorter than 7 days, with no mortality. Complications are listed in Table 3.

TABLE 2. BAROS scores in 120 obese subjects after a 2-year follow-up following RYGB

\begin{tabular}{lccccc}
\hline \multicolumn{1}{c}{ Gender } & BAROS \%EWL & BAROS QoL & $\begin{array}{c}\text { BAROS Control } \\
\text { Comorbidities }\end{array}$ & $\begin{array}{c}\text { BAROS } \\
\text { Complications }\end{array}$ & Total BAROS \\
\hline Men $(\mathrm{n}=17)$ & $2.12( \pm 0.70)$ & $2.08( \pm 0.75)$ & $1.24( \pm 1.39)$ & $-0.13( \pm 0.33)$ & $5.3( \pm 1.5)$ \\
Women $(\mathrm{n}=103)$ & $2.52( \pm 0.57)$ & $2.36( \pm 0.68)$ & $1.77( \pm 1.44)$ & $-0.13( \pm 0.30)$ & $6.6( \pm 1.7)$ \\
Total $(\mathrm{n}=120)$ & $2.47( \pm 0.61)$ & $2.32( \pm 0.69)$ & $1.69( \pm 1.44)$ & $-0.13( \pm 0.30)$ & $6.4( \pm 1.7)$ \\
Mann-Whitney U test & $\begin{array}{c}\text { Mann-Whitney } \\
(P=0.018)\end{array}$ & $\begin{array}{c}\text { Mann-Whitney } \\
(P=0.140)\end{array}$ & $\begin{array}{c}\text { Mann-Whitney } \\
(P=0.110)\end{array}$ & $\begin{array}{c}\text { Mann-Whitney } \\
(P=0.586)\end{array}$ & $\begin{array}{c}\text { Mann-Whitney } \\
(P=0.005)\end{array}$ \\
\hline
\end{tabular}

RYGB: Roux-en-Y gastric bypass. EWL: excess weight loss. QoL: quality of life.

Associated with the highest scores in BAROS \%EWL observed in women $($ mean $=2.52 \pm 0.57)$ as compared to men $($ mean $=2.12$ $\pm 0.70)(P=0.018)$, followed by a tendency to relatively better satisfaction in women concerning items of quality of life (although not significant, $P=0.14$ ). However, there were no significant differences between gender regarding partial BAROS scores involving QoL, control of comorbidities, or clinical/surgical complications.

Regarding pre-surgical comorbidities described as categorical data, within male patients $(\mathrm{n}=17), 9(53 \%)$ showed no comorbidities, $3(18 \%)$ cardiovascular, $2(12 \%)$ metabolic syndromes, and 1 $(6 \%)$ pulmonary/lung conditions. Only two male subjects showed association of 2 comorbidities (cardiovascular and metabolic, $12 \%)$. In the group of women $(n=103)$, there were $40(39 \%)$ cases without comorbidities, $23(22 \%)$ cases with cardiovascular, $6(6 \%)$ with osteoarticular, $4(4 \%)$ with metabolic, $2(2 \%)$ with gastrointestinal, and $1(1 \%)$ with pulmonary clinically relevant conditions. Sixteen women showed association between cardiovascular and metabolic disorders $(15.5 \%)$ and $4(4 \%)$ between cardiovascular and osteoarticular disorders. Two women showed association between trhee or more comorbidities.

From the eight men presenting pre-surgical comorbidities, there was full resolution in five $(62.5 \%)$ cases and partial resolution in three $(37.5 \%)$ cases. From the 63 women with pre- surgical comorbidities, $56(89 \%)$ cases showed complete resolution and seven $(11 \%)$ cases partial resolution of comorbidities. Overall, from the $71(59 \%)$ subjects suffering from pre- surgical conditions, complete (61 [86\%] cases) or partial resolution (10 [14\%] cases) was observed in all subjects.

The analysis of surgical and/or clinical complications showed that in 92 subjects (13 [76.5\%] men and 89 [74.2\%] women) there were no complications at all. Concerning the complications strictly arising from the surgery, reoperation due to bowel obstruction was needed in two patients (1.7\% of total casuistic) and there were three $(2.5 \%)$ cases of stomal stenosis, solved by endoscopic dilation. Therefore, complications specifically resulting from the surgical procedure were observed in $4.2 \%$ of cases.

Along the 2-year follow-up, nine $(7.5 \%)$ patients showed incidental cholelitiasis and needed cholecystectomy. Sixteen $(13 \%$ of total casuistic) subjects presented minor clinical complications managed by means of outpatient treatment ( 1 man and 15 women).
TABLE 3. Surgical and clinical complications according to BAROS criteria in 120 morbidly obese patients who underwent RYGB after a 2-year follow-up.

\begin{tabular}{lcc}
\hline & Complications & N $(\%)$ \\
\hline $\begin{array}{l}\text { SURGICAL } \\
\text { Major (-1.0) } \\
\text { Early } \\
\text { Late }\end{array}$ & Bowel obstruction $(*)$ & $2(1.7 \%)$ \\
& --- & --- \\
Minor $(-0.2)$ & & \\
Early & --- & --- \\
Late & Stomal stenosis & $3(2.5 \%)$
\end{tabular}

\section{CLINICAL}

Major (-1.0)

Early

Pulmonary embolism

$1(0.8 \%)$

Late

$---$

Minor (-0.2)
Early

$$
\begin{gathered}
\text { Deep venous thrombosis } \\
\text { Dysfagia } \\
\text { Urinary tract infection } \\
\text { Persistent nausea and vomiting }
\end{gathered}
$$

Late

Anemia
Renal lithiasis
Metabolic deficiency
Depression

Incidental

Cholelithiasis*

$(-1.0)$

Late
After bariatric surgery

(2 year- follow up)
$2(1.7 \%)$

$1(0.8 \%)$

$1(0.8 \%)$

$1(0.8 \%)$

$7(5.8 \%)$

$1(0.8 \%)$

$2(1.7 \%)$

$1(0.8 \%)$
RYGB: Roux-en-Y gastric bypass. * Choletithiase is not considered as a complication of bariatric surgery 
Thus, total scores of the BAROS scale allowed good ( 28 cases [23\%]), very good (38 [32\%] cases) or excellent results (53 [44\%] cases) in $99 \%$ of the total sample (119 cases). (Table 4$)$

TABLE 4. Results concerning total score of BAROS showed in categorical data of 120 subjects submitted to RYGB at the end of a 2-year follow-up period

\begin{tabular}{lcccc}
\hline $\begin{array}{l}\text { Total BAROS } \\
\text { Categorical } \\
\text { data }\end{array}$ & Acceptable & Good & Very good & Excellent \\
\hline $\begin{array}{l}\text { Man } \\
(\mathrm{n}=17)\end{array}$ & 0 & $\begin{array}{c}9 \\
(7.5 \%)\end{array}$ & $\begin{array}{c}3 \\
(2.5 \%)\end{array}$ & $\begin{array}{c}5 \\
(4.2 \%)\end{array}$ \\
$\begin{array}{l}\text { Women } \\
(\mathrm{n}=103)\end{array}$ & 1 & 19 & 35 & 48 \\
& $(0.8 \%)$ & $(15.8 \%)$ & $(29.2 \%)$ & $(40 \%)$ \\
$\begin{array}{l}\text { Total } \\
(\mathrm{n}=120)\end{array}$ & 1 & 28 & 38 & 53 \\
\hline
\end{tabular}

RYGB: Roux-en-Y gastric bypass. $\mathrm{X}^{2}=9.8 ; P=0.020$.

\section{DISCUSSION}

\section{Weight loss}

After a period of 2 years, patients showed mean $\%$ EWL of $74.6( \pm 15.9)$ and BMI reduction of $15.6( \pm 4.4)$. These results are similar to those found in literature. Indeed, a recent metanalysis has reported mean $\%$ EWL of $74.4 \%$ and BMI reduction of 14.5 in randomized controlled studies of patients underwent gastric bypass after 2-years of follow-up ${ }^{(5)}$.

Overall, literature reports that male gender and age are negatively associated with weight loss after bariatric procedures ${ }^{(3)}$. Our study showed that women drop a higher percentage of excess weight when compared to men. There was also a trend to the same effect with reference to BMI reduction. However, since those differences in BMI reduction showed just a non-significant trend to higher reduction of weight in women $(\mathrm{F}=2.7 ; P=0.102)$ as well as higher $\%$ EWL That seems to be partially resulting from the lower baseline mean excess weight of women comparatively to men. On the other hand, controlling for pre-surgical $\mathrm{BMI}$, we have found trends to negative correlations between age and $\% \mathrm{EWL}(\mathrm{R}=-0.160 ; P=0.083)$ and age and $\mathrm{BMI}$ reduction $(\mathrm{R}=-0.165 ; P=0.073)$.

\section{Outcome variables according to BAROS scores}

We have used the Bariatric Analysis and Reporting Outcome System (BAROS) in order to access variables impacting outcome results of bariatric surgery. Improvement of co-morbid conditions associated with obesity is one of the most important variables considered in the success of bariatric treatment. In the present sample of subjects, from 71 cases with one or more co-morbidites associated to obesity, there were complete remission in $61(86 \%)$ cases and partial resolution in $10(14 \%)$ cases.

With reference to complications strictly arising from the surgery ( $4.2 \%$ of cases), reoperation was needed in two patients $(1.7 \%$ of total casuistic) due to bowel obstruction and three in cases due to stomal stenoses (treated through endoscopic dilation). Along the follow-up, nine patients showed cholelitiasis and needed cholecystectomy. Sixteen (13\% of total casuistic) subjects presented minor clinical complications managed by means of outpatient six treatment (one man and 15 women). On the other hand, one $(0.8 \%$ of total casuistic) patient suffered a major clinical complication requiring hospital admission due to pulmonary embolism. All complications were treated clinically or surgically, with admissions to hospital lasting less than 7 days. No deaths were documented.

Regarding total scores obtained with the BAROS questionnaire, results were considered excellent by $44 \%$ of patients, very good by $32 \%$, good by $23 \%$, and acceptable by one $(0.8 \%)$ patient. Overall, the majority of patients $(99 \%)$ presented with scores varying from good to excellent. This result seems to be consistent with other studies, as e.g., the study of Suter and colleagues ${ }^{(21)}$. That particular study involved 379 patients undergoing RYGB in Switzerland, and it found that more than $95 \%$ of patients had a good to excellent 5 -year overall result according to the BAROS score.

\section{Changes in QoL}

Several surgical teams have been using the BAROS system in the follow-up of bariatric patients in order to analyse quality of life variables. In our study, in spite of gender, subjects scored a mean of $2.32(\mathrm{SD}=0.69)$ in the items of QoL. According to the BAROS scalar ranking for QoL evaluation, most of patients rated their condition as improved or much improved. Again, the mean score related to QoL in our sample was similar to those presented in the latest literature ${ }^{(21)}$.

Finally, it is wise to point out some of the limitations of our study: Putative (?) characteristics of patients that may impact results concerning weight loss and QoL, such as ethnicity, fat mass, physical activity, level of education, and psychiatric state were not documented. Other than that, the casuistic of male subjects was relatively small compared to women, and a longer period of follow-up would be advisable in order to assess the stability of results.

\section{CONCLUSION}

The present study, based on the follow-up of 120 patients 2 years after underwent to RYGB, confirms previous results concerning efficacy and safety of bariatric surgery in the control of obesity and related conditions. The mortality rate was zero. Patients showed mean $\%$ EWL of $75 \%$ and total or partial control of clinical conditions in all 71 cases suffering from pre- surgical co-morbidities. This surgical procedure proved to be safe, with $4.2 \%$ percent of cases presenting with complications specifically related to the surgical procedure. Sixteen (13\% of the total casuistic) subjects experienced clinical complications requiring clinical outpatients treatment ( $9.1 \%$ of the total patients) or in some cases including hospital admission (6.9\% of the total patients). As reported by a number of studies, using the BAROS system allows us to identify good to excellent results concerning items of quality of life and overall satisfaction. We have also found that both male gender and age can be associanted with poor results as far as weight reduction. Based on our experience and medical literature, it is recommended that future studies also investigate other important variables impacting the outcome of bariatric interventions, such as medical (e.g., fat mass), psychosocial (e.g., education, income, depression, compulsive eating) ${ }^{(8,20)}$, ethnic, and lifestyle (e.g., inactivity, overeating), in order to better identify influential variables and risk factors over longer periods of follow-up. 


\section{ACKNOWLEDGEMENTS}

We acknowledge the Vitória Hospital Staff specially Dr. Marcio Arruda, Dr. Pedro Roberto Fausto, Dr. Vinicius Ferreira da Rocha and Dr. Nelcy do Amaral for logistic support and Dra. Flávia Carvalho Silveira for the text revision and scientific contributions.

\section{Authors' contributions}

Queiroz C: research idealizer, data collector, data processor. Sallet JA: literature review, statistic reviewer article reviewer. de Barros e Silva PGM: article production, data processor. Queiroz LGPS: data collector, article production. Pimentel JA: corresponding author, literature review, article production. Sallet. PC: translator, article production, technical reviewer.

Queiroz C, Sallet JA, de Barros e Silva PGM, Queiroz LGPS, Pimentel JA, Sallet. PC. Aplicação do questionário BAROS em pacientes obesos submetidos à cirurgia bariátrica com 2 anos de evolução. Arq Gastroenterol. 2017,54(1):60-4.

RESUMO - Contexto - Nas últimas décadas, a alta prevalência de obesidade na população geral trouxe grandes preocupações para a saúde pública. Contrariamente ao tratamento convencional envolvendo dieta e atividade física, quase sempre inefetivo em gerar resultados a longo prazo, a cirurgia bariátrica vem se mostrando um método efetivo de perda de peso mantida em indivíduos com obesidade mórbida. O Bariatric Analysis and Reporting Outcome System (BAROS) é um sistema reconhecido e objetivo para a avaliação global de resultados depois de cirurgia bariátrica. Objetivo - Investigar os resultados referentes à casuística de pacientes obesos mórbidos submetidos à cirurgia bariátrica em um período de 2 anos em termos de perda de peso, condições clínicas relacionadas, segurança e qualidade de vida. Métodos - Um total de 120 pacientes obesos (17 masculinos e 103 femininos) admitidos consecutivamente durante período de 4 meses para cirurgia bariátrica foram avaliados e investigados usando o sistema BAROS após 2 anos de evolução. Resultados - Os pacientes apresentaram redução média percentual de excesso de peso de 74,6 $( \pm 15,9)$ \% e redução média de índice de massa corporal de $15,6( \pm 4,4) \mathrm{Kg} / \mathrm{m}^{2}$. Comorbidades pré-cirúrgicas estavam presentes em $71(59 \%)$ pacientes e em todos eles foram total ( $86 \%$ ) ou parcialmente (14\%) resolvidas. Complicações resultantes especificamente do procedimento cirúrgico foram observadas em $4,2 \%$ dos casos (duas obstruções intestinais exigindo reoperação e três estenoses anastomóticas resolvidas com dilatação endoscópica). Dezesseis (13\%) pacientes apresentaram complicações clínicas menores resolvidas com manejo clínico ambulatorial. Os escores totais do BAROS classificaram os resultados como excelente até bom em $99 \%$ dos casos ( $44 \%$ excelente, $38 \%$ muito bom e $23 \%$ bom) e aceitável em $1 \%$ dos casos. Conclusão - De acordo com o questionário BAROS, a cirurgia bariátrica se mostrou segura e efetiva no controle da obesidade e de comorbidades clínicas associadas, permitindo satisfação geral dos pacientes após 2 anos de seguimento. Estudos futuros deverão também investigar outras variáveis clínicas e psicossociais de possível impacto na evolução e por períodos de seguimento mais longos.

DESCRITORES - Obesidade mórbida. Cirurgia bariátrica. Peso corporal. Qualidade de vida.

\section{REFERENCES}

1. Al Harakeh AB, Larson CJ, Mathiason MA, Kallies KJ, Kothari SN. BAROS results in 700 patients after laparoscopic Roux-en-Y gastric bypass with subset analysis of age, gender, and initial body mass index. Surg Obes Relat Dis. 2011;7:94-8.

2. Anderson T, Backer OG, Stockholn KH. Randomized trial of gastroplasty compared with diet alone in morbid obesity. N Engl J Med. 1984;310:352-6.

3. Ballantyne GH. Measuring outcomes following bariatric surgery: weight loss parameters, improvement in co-morbid conditions, change in quality of life and patient satisfaction. Obes Surg. 2003;13:954-64.

4. Batterman RL, Cowley MA, Small CJ, et al. Gut hormone PYY3-36 physiologically inhibits food intake. Nature. 2002;418:650-4.

5. Chang SH, Stoll CR, Song J, Varela JE, Eagon CJ, Colditz GA. The effectiveness and risks of bariatric surgery: an updated systematic review and meta-analysis, 2003-2012. JAMA Surg. 2014;149:275-87.

6. Colquitt JL, Pickett K, Loveman E, Frampton GK. Surgery for weight loss in adults (Review). Cochrane Database of Systematic Reviews 2014, Issue 8. Art. No.: CD003641. DOI: 10.1002/14651858.CD003641.pub4.

7. Deitel M, Shikora SA. The development of surgical treatment of morbid obesity. J Am Coll Nutr. 2002;21:365-71.

8. Gordon PC, Sallet JA, Sallet PC. The impact of temperament and character inventory personality traits on long-term outcome of Roux-en-Y gastric bypass. Obes Surg. 2014;24:1647-55

9. Greenstein RJ, Rabner JG, Taler Y. Bariatric surgery vs conventional dieting in the morbidly obese. Obes Surg. 1994;4:16-23.

10. Juhaeri SJ, Chambless, Taylor HA, et al. Weight change among self-reported dieters and non-dieters in white and African American men and women. Eur J Epidemiol. 2001;17:917-23.

11. Kelly T, Yang W, Chen CS, Reynolds K, He J. Global burden of obesity in 2005 and projections to 2030. Int J Obes (Lond). 2008;32:1431-7.
12. Mancini MC. Bariatric surgery - An update for the endocrinologist. Arq Bras Endocrinol Metab. 2014;58:875-88.

13. Marcelino LF, Patricio ZM. A complexidade da obesidade e o processo de viver após a cirurgia bariátrica: uma questão de saúde coletiva. Ciênc. Saúde Coletiva [Internet]. 2011, vol.16, n.12, pp. 4767-4776. ISSN 1413-8123. http://dx.doi org/10.1590/S1413-81232011001300025.

14. Marchesini JB, Nicareta JR. Comparative study of five different surgical techniques for the treatment of morbid obesity using BAROS. Arq Bras Cir Dig. 2014;27(Suppl. 1):17-20

15. Metropolitan height and weight tables. Stat Bul Metrop Live Found. 1983, v.64, n.1, p.3-9.

16. Oliveira MRM, Fortes RC. [Effects of Reducing Gastric Intestinal Bypass with Roux-Y on severe obesityand metabolic syndrome: a literature review] Comun Ciênc Saúde. 2013;24:267-80

17. Oria HE, Moorehead MK. Bariatric analysis and reporting outcome system. Obes Surg. 1998;8:487-99.

18. Oria HE, Moorehead MK. Updated Bariatric Analysis and Reporting Outcome System (BAROS). Surgery for Obesity and Related Diseases. 2009(5):60-6.

19. Pizani CE, Sallet JA, Sallet PC. Laparoscopic surgery of the small bowel. In: Eldo E Frezza; Michel Gagner; Michel K W Li (Org.). Internationa principles of laparoscopic surgery. Woodburry: Ciné-Med Publishing. 2009; p. $547-56$

20. Sallet PC, Sallet JA, Dixon JB, Collis E, Pisani CE, Levy A, Bonaldi FL, Cordás TA. Eating behavior as a prognostic factor for weight loss after gastric bypass. Obes Surg. 2007; 17:445-51.

21. Suter M, DonadiniA, Romy S, Demartines N, Giusti V. Laparoscopic RouxEn-Y Gastric Bypass. Significant Long-Term Weight Loss, Improvement of Obesity-Related Comorbidities and Quality of Life. Ann Surg. 2011;254 267-73. 